\title{
PRELIMINARY PHYTOCHEMICAL SCREENING AND GAS CHROMATOGRAPHY AND MASS SPECTROMETRY ANALYSIS OF CHLOROFORM EXTRACT OF GARCINIA CAMBOGIA FRUITS
}

\author{
PRIYADHARISINI J ${ }^{1,2 *}$ \\ ${ }^{1}$ Shri JagdishPrasad Jhabarmal Tibrewala University, Institute of Pharmacy, Jhunujunu, Rajasthan, India. ${ }^{2}$ Department of Pharmaceutical \\ Chemistry, Gautham College of Pharmacy, Bengaluru, Karnataka, India. Email: kamalpriyadharisini@gmail.com
}

Received: 05 April 2019, Revised and Accepted: 20 May 2019

\section{ABSTRACT}

Objective: Garcinia cambogia fruit commonly known as Malabar tamarind, belongs to the family Clusiaceae, is said to show varied medicinal effects including antiobesity, antiviral, antimicrobial, anti-inflammatory, and anticancer. Hence, the present study deals with the determination of phytochemical constituents present in the chloroform extract of $G$. cambogia fruits and determination of bioactive compounds using the gas chromatography and mass spectrometry analysis (GC-MS) technique.

Methods: The phytochemical constituents present in the chloroform extract of G. cambogia fruits were tested by qualitative analysis, and bioactive compounds were investigated using the GC-MS technique. The analysis was carried out on a JOEL GC MATERI system with a column packed with a column HP5MS (5\% phenyl, methylpolysiloxane) fused capillary column $(30 \times 0.25 \mu \mathrm{m} \mathrm{ID} \times 0.25 \mu \mathrm{m} \mathrm{df})$. The compounds are separated using helium as a carrier gas at a constant flow $1 \mathrm{ml} / \mathrm{min}$. The mass spectra of the known compounds in the fruit extract were matched with the known components stored in the National Institute of Standard and technology library.

Results: The phytochemical test revealed the presence of xanthones, flavonoids, phlobatannins, terpenoids steroids, phenolic compounds saponins, and anthraquinones. The GC-MS analysis provided peaks of 13 different bioactive compounds, namely 3,7,11,15-tetramethyl-2-hexadecenol (37.1\%), pentadecanoic acid 14-methyl-, methylester (100\%), hexadecanoic acid 15 methyl-, methyl ester (100\%), 9,12-octadecadienoic acid methyl ester (42.6\%), docosanoic acid (100\%), docosanoic acid methyl ester (37.3\%), phenol, 2,4,bis1,1-dimethylethyl) (100\%), 9, hexadecanoic acid methyl ester (99.2\%), 10-octadecenoic acid methylester (100\%), 11 eicosenoic acid methyl ester (53.1\%), heptadecanoic acid 9 methyl-, methyl ester (100\%), eicosenoic acid methyl ester (56.9\%), and 5, 12d ethanofuro oxepino[2,3,4-mn] (2,3,4-ed) anthrace2-one 9,12-dilol 6 methyl,2a $3,4,4 a, 5,6,7,8 a-o c t a h y d r o ~(19 \%)$ were reported.

Conclusion: The phytochemical investigation and determination of bioactive compounds will be considered for pharmacological activities, and further isolation of individual components would however help to find new drugs.

Keywords: Garcinia cambogia, Bioactive compounds, Gas chromatography and mass spectrometry analysis analysis.

(c) 2019 The Authors. Published by Innovare Academic Sciences Pvt Ltd. This is an open access article under the CC BY license (http://creativecommons. org/licenses/by/4. 0/) DOI: http://dx.doi.org/10.22159/ajpcr.2019.v12i7.33466

\section{INTRODUCTION}

Medicinal plants are an expensive gift from humans to nature. Chemotherapeutic agents contain potential compounds of traditional medicines [1]. Medicinal plants have been used by traditional medical practitioners for many years in daily life to treat disease globally $[2,3]$. For the treatment and prevention of various ailments, particularly in developing countries where infectious diseases are endemic and modern health facilities are inadequate.

According to the World Health Organization 2008, more than $80 \%$ of the world's population relies on traditional medicine for their primary healthcare needs [4]. With the associated side effects of modern medicine, traditional medicines are gaining importance and are now being studied to find the scientific basis of their therapeutic actions [5]. It has been shown that the in vitro screening methods could provide the needed preliminary observation to select crude plant extracts with potential useful properties for further chemical and pharmacological investigation $[6,7]$.

The plant Garcinia cambogia belongs to family Guttiferae (Clusiaceae). It is a wild subtropical tropical plant. The plants are shrubs or trees with yellow-greenish juice [8]. G. cambogia (Gaertn.) Desr. famously known as Malabar tamarind or Kodampuli is a member of family Clusiaceae (Guttiferae) and distributed throughout the world [9]. The fruits of $G$. cambogia are yellowish, large, and globular with deep vertical grooves enclosing 6-8 multilobed seeds. According to literature review,
G. cambogia possesses various number of pharmacological activities which includes antiobesity, antimicrobial, anticancer, anti-Alzheimer, anti-inflammatory, hepatoprotective, and anti-HIV activities [10].

Mass spectrometry coupled with chromatographic separation such as gas chromatography and mass spectrometry analysis [GC-MS] is normally used for direct analysis of components existing in traditional medicines and medicinal plants [11]. Since there is no report on the GC-MS analysis of bioactive compounds present in the chloroform fraction of G. cambogia fruit extract, it was chosen as the subject study.

Thus, the aim of present work was to identify the phytochemicals present in the chloroform extract of the fruits of $G$. cambogia by qualitative phytochemical testing and to identify the bioactive compounds by GC-MS method (gas chromatography coupled with mass spectrometry.

\section{METHODS}

\section{Collection of fruits}

The G. cambogia fruits were collected in the month of July from Thrissur, Kerala, India. The plant material was identified and authenticated by GKVK, Bengaluru. The voucher specimen bearing the reference number UASB-4551 is acknowledged in the herbarium file of the department.

The fruits were washed with running tap water and distilled water and cut into slices using a stainless steel knife. The pericarp of the 
G. cambogia species was removed, and the seeds were separated. The pericarp was shade dried for a period of 60 days.

\section{Preparation of the crude extract}

Pericarp was dried and it was powdered coarsely in a mixer grinder. The powder was stored in an airtight container and used for further extraction. About $100 \mathrm{~g}$ of powder of the pericarp was extracted with $1000 \mathrm{ml}$ of chloroform for a period of $6 \mathrm{~h}$ using a Soxhlet apparatus. The chloroform crude extract was evaporated to dryness in a rotatory vacuum evaporator under reduced pressure and was stored at $4^{\circ} \mathrm{C}$ for further use. The chloroform extract was subjected to a qualitative phytochemical investigation. The chloroform extract contains polar components, and a sample volume of $2 \mu \mathrm{l}$ was used for GC-MS analysis of chemical components.

\section{Phytochemical analysis}

The extract was subjected to preliminary phytochemical tests qualitatively for xanthones, flavonoids, terpenoids steroids, saponins, and anthraquinones in our laboratory by common methods and chemicals $[12,13]$.

\section{Gas chromatography and mass spectrometry analysis (GC-MS)} analysis

GC-MS analysis of the chloroform extract of G. cambogia was performed in a JEOLGC MATE-II, and a gas chromatogram interfaced to a mass spectrometer (GC-MS) equipped with HP5MS (5\% phenyl) methyl polysiloxane fused capillary column (30 $\times 0.25 \mu \mathrm{m}$ ID $\times 0.25 \mu \mathrm{m} \mathrm{df})$. For GC-MS detection, an electron ionization system was operated in electron impact mode with ionization energy of $70 \mathrm{eV}$ [14]. The carrier gas used in the analysis was helium (99.999\%) at a constant flow rate of $1 \mathrm{ml} / \mathrm{min}$, and an injection volume of $2 \mu \mathrm{ml}$ was employed. The injector temperature was maintained at $220^{\circ} \mathrm{C}$, the ion source temperature was $250^{\circ} \mathrm{C}$, and the oven temperature was programmed from $50^{\circ} \mathrm{C}$ to $250^{\circ} \mathrm{C}$ with an increase of $10^{\circ} \mathrm{C}$ per minute. Mass spectra were taken at $70 \mathrm{eV}$, a scanning interval of $0.5 \mathrm{~s}$, and fragments from 45 to $450 \mathrm{Da}$. The solvent delay was 0-2 min, and the total GC-MS running time was $36 \mathrm{~min}$. The mass analyzer used was quadrupole double focusing mass analyzer; the detector used was photomultiplier tube; and the software adapted to handle mass spectra and chromatograms was a Turbo-Mass ver-5.2.

\section{Identification of phytocomponents}

Interpretation on mass spectrum GC-MS was conducted using the database of National Institute standard and technology (NIST) having more than 62,000 patterns [15]. The spectrum of the known compounds stored in the NIST library. The name, molecular weight, and structure of components of test materials were ascertained.

\section{RESULTS AND DISCUSSION}

The phytochemical constituents such as xanthones, flavonoids, terpenoids steroids, saponins, and anthraquinones are found in fruit extract of this plant, and the results are tabulated in Table 1.
The GC-MS chromatogram of the compounds with their peaks is shown in Fig 1. The results of peak area \%, retention time, molecular formula, and molecular weight of 13 compounds present in GC-MS analysis which are tabulated in Table 2 .

Previous studies shown that GC-MS analysis of G. cambogia methanolic fruit revealed the presence of forty compounds [8]. Hence, difference in the bioactive compounds might arise due to the difference in organic solvent extraction. From the results, the prevailing compounds 9,12-octadecadienoic acid (linoleic acid) shown to have anti-inflammatory, hypocholesterolemic, cancer preventive, hepatoprotective, nematicide, antihistaminic antieczema, antiacne, and hexadecanoic acid alkyl ester shown to have antioxidant, antimicrobial, anti-inflammatory, anticancer diuretic, and hemolytic properties.

\section{CONCLUSION}

There is a growing awareness in correlating the bioactive compounds and their biological activities [16,17]. In the olden days itself, the importance of medicinal plants has been discovered. Plants are rich in medicinal properties, and they are useful in human health and wellbeing. Treating of diseases through natural medicine is the most ancient treatment known to mankind. Traditional plant-based medicines for primary health-care need are followed in underdeveloped countries of about $80 \%$ of world population [18]. Extraction is the main step for the recovery and isolation of bioactive phytochemicals from plant materials before component analysis [19]. The gas chromatogram method can serve as an interesting tool for testing the number of active principles of herbs.

Thus, this study explores the goodness of the G. cambogia fruit which has commendable sense of purpose. Further investigation for isolation

Table 1: Phytochemical constituents of chloroform extract of Garcinia cambogia fruits

\begin{tabular}{lll}
\hline S.No. & $\begin{array}{l}\text { Phytochemical } \\
\text { components }\end{array}$ & $\begin{array}{l}\text { Chloroform extract of } \\
\text { Garcinia cambogia }\end{array}$ \\
\hline 1 & Xanthones & + \\
2 & Flavonoids & + \\
3 & Phlobatannins & + \\
4 & Terpenoids & + \\
5 & Steroids & + \\
6 & Phenols & + \\
7 & Saponins & + \\
8 & Anthraquinones & - \\
9 & Carbohydrates & - \\
10 & Proteins & - \\
11 & Tannins & - \\
12 & Amino acids & \\
\hline
\end{tabular}

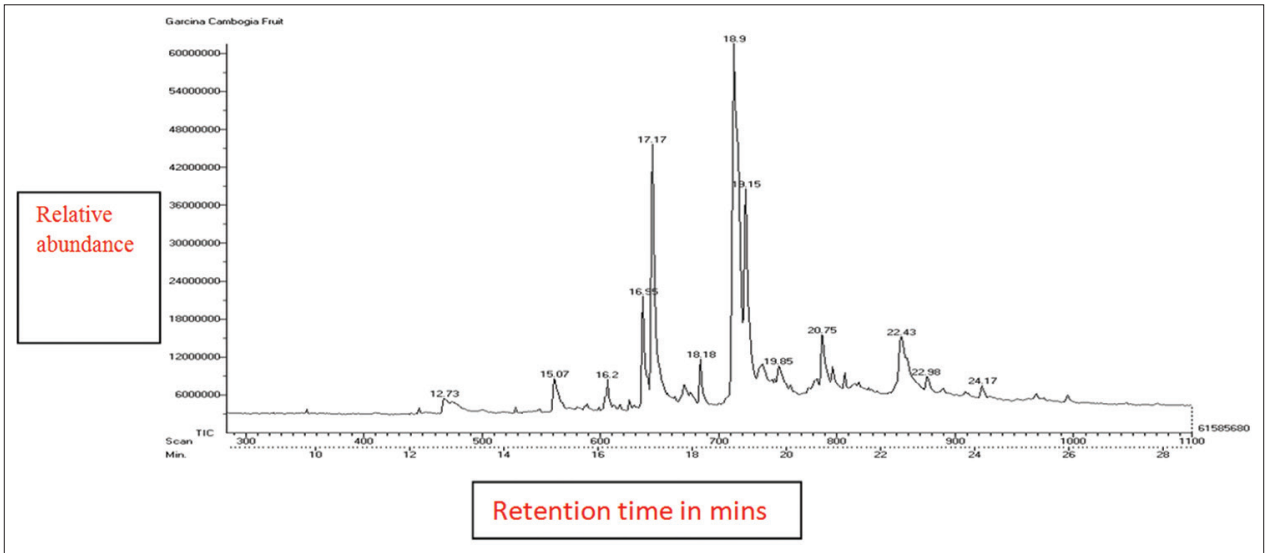

Fig. 1: Chromatogram obtained from the gas chromatography and mass spectrometry analysis with extract of $G$. cambogia fruits 
Table 2: Gas chromatography-mass spectrometry bioactive compounds of Garcinia cambogia fruits chloroform extract

\begin{tabular}{|c|c|c|c|c|c|}
\hline S.No. & Name of the compound & RT & Peak area $\%$ & MF & MW \\
\hline 1 & $3,7,11,15$ tetramethyl-2-headecent 1 -ol & 16.22 & 37.1 & $\mathrm{C}_{20} \mathrm{H}_{40} \mathrm{O}_{1}$ & 296.0 \\
\hline 2 & Pentadecanoic acid 14 methyl, methyl ester & 17.23 & 100.0 & $\mathrm{C}_{17}^{20} \mathrm{H}_{36}^{40} \mathrm{O}_{2}$ & 272.0 \\
\hline 3 & Hexadecanoic acid 15 methyl-, methyl ester & 18.18 & 100.0 & $\mathrm{C}_{17} \mathrm{H}_{32} \mathrm{O}_{2}$ & 268.0 \\
\hline 4 & 9,12-octadecadienoic acid methyl ester & 19.85 & 42.6 & $\mathrm{C}_{18} \mathrm{H}_{34}^{32} \mathrm{O}_{2}^{2}$ & 282.0 \\
\hline 5 & Docosanoic acid & 22.43 & 100.0 & $\mathrm{C}_{22} \mathrm{H}_{43} \mathrm{O}_{2}$ & 339.0 \\
\hline 6 & Docosanoic acid methyl ester & 22.98 & 37.3 & $\mathrm{C}_{23}^{22} \mathrm{H}_{46}^{43} \mathrm{O}_{2}^{2}$ & 354.0 \\
\hline 7 & Phenol 2,4-bis (1,1 dimethylethyl) & 12.73 & 100.0 & $\mathrm{C}_{14}^{23} \mathrm{H}_{22} \mathrm{O}_{1}$ & 206.0 \\
\hline 9 & 10-octadecenoic acid methyl ester & 18.97 & 100.0 & $\mathrm{C}_{19}^{16} \mathrm{H}_{36}^{34} \mathrm{O}_{2}^{2}$ & 296.0 \\
\hline 10 & 11-eicosenoic acid methyl ester & 20.75 & 53.1 & $\mathrm{C}_{21}^{19} \mathrm{H}_{30} \mathrm{O}_{2}$ & 323.0 \\
\hline 11 & Heptadecanoic acid 9 methyl-, methyl ester & 19.17 & 100.0 & $\mathrm{C}_{19}^{21} \mathrm{H}_{38}^{39} \mathrm{O}_{2}^{2}$ & 298.0 \\
\hline 12 & Eicosanoic acid methyl ester & 20.98 & 56.9 & $\mathrm{C}_{21} \mathrm{H}_{42} \mathrm{O}_{2}$ & 326.0 \\
\hline 13 & $\begin{array}{l}\text { 5,12d ethano furo[2,3, m, n oxepino 2,3,4-ed] anthracene } 2 \text {-one } 9,12 \text { dilol } \\
6 \text { methyl }(3,44 \mathrm{a}, 5,6,7,8) \text { octa hydro }\end{array}$ & 24.17 & 19 & $\mathrm{C}_{21}^{21} \mathrm{H}_{24}^{42} \mathrm{O}_{5}^{2}$ & 356.0 \\
\hline
\end{tabular}

RT: Retention time, MF: Molecular formula, MW: Molecular weight

of individual bioactive compounds may pave a way for finding a novel drug.

\section{ACKNOWLEDGMENT}

First, I would like to show my gratitude to Gautham College of Pharmacy for giving support to carry out the research work and I am thankful to Sophisticated Analytical Instrumentation Facility IIT, Chennai, for carrying out GC-MS Analysis.

\section{AUTHOR'S CONTRIBUTION}

The idea of research, execution of results, data interpretation, and manuscript writing was contributed by J. Priyadharisini.

\section{COMPETING OF INTERESTS}

Declared none.

\section{REFERENCES}

1. Sudhakar M, Bolkiah R. Phytochemical determination of polyherbal extract using FTIR and Gc-MS analysis. Eur J Pharm Res 2015;5:173-8.

2. Das TS, Ramesh L, Agastian P. Gc-MS analysis of bioactive constituents of Aristolochia bracteolata Linn with in vitro antioxidant properties. J Appl Pharm Sci 2016;6:61-8.

3. Krishnaiah GM, Prashanth GK. Phytochemical studies, and GC-MS analysis of the leaf extracts of Melia azedarach Linn. Int J Adv Eng Technol Manage Appl Sci 2014;1:48-54.

4. Anand D, Johnson W, Saravanan P, Rajarajan S. Phytochemical analysis of leaf extract Eclipta alba (L.) Hassk by GC-MS method. Int J Pharmacogn Phytochem Res 2014;6:562-6.

5. Rukshana MS, Dossa A, Rani TP. Phytochemical screening and GC-MS analysis of leaf extract of Pergularia daemia (Forssk) (Chiov). Asian J Plant Sci Res 2017;7:9-15.

6. Ammal RM, Bai GV. GC-MS determination of bioactive constituents of Heliotropium indicum leaf. J Med Plant Stud 2013;1:30-3.

7. Komalavalli T, Lincy P, Kumarasamy SM, Mohan VR. Determination of bioactive components of anastasia Travancorica Bedd (acanthaceae) by GC-MS analysis. Int J Pharm Clin Res 2014;6:155-8.

8. Irulandi K, Anatharaj S, Selvan T, Mehalingan P. GC-MS analysis and phytochemical studies of methanolic fruits extract of Garcinia cambogia Hart. EX Boerl and Ziziphus trinervia Roth. J Adv Appl Sci Res 2016;2:90-5.

9. Choppa T, Selvaraj CI, Zachariah A. Evaluation and characterization of Malabar tamarind [Garcinia cambogia (Gaertn.) Desr.] seed oil. J Food Sci Technol 2015;52:5906-13.

10. Jamila N, Choi JY, Hong JH, Nho EY, Khan N, Jo CH, et al. Identification and quantification of adulteration in Garcinia cambogia commercial products by chromatographic and spectrometric methods. Food Addit Contam Part A Chem Anal Control Expo Risk Assess 2016;33:1751-60.

11. Vardharaj V, Kupan M. Identification and determination of bioactive phytochemical constituents from the hydroalcholic extract of Achyranthes aspera whole plant by gas chromatography-mass spectrometry analysis. Asian J Pharm Clin Res 2015;8:125-9.

12. Harborne JB. Phytochemical Methods. London: Chapman and Hall, Ltd.; 1973. p. 49-88.

13. Krishnamoorthy V, Nagappan P, Serene AK, Rajendran R. Preliminary phytochemical screening of the fruit rind of Garcinia cambogia and leaves of Bauhinia variegata - a comparative study. Int J Curr Microbiol Appl Sci 2014;3:479-86.

14. Sahani K, Thakur D. GC-MS analysis of endophytic fungi Curvularia aeria MTCC12847 isolated from Tribulus terrestris L. Int J Pharm Pharm Sci 2019;11:26-32.

15. Chidambaram V, Niraimathi L, Sudha V, Lavanya R, Vadivel V, Brindha P. Spectrophotometric, HPTLC, and GC-MS studies on selected spice extracts. Int J Pharm Pharm Sci 2015;7:184-90.

16. Kalimuthu K, Prabakaran R. Preliminary phytochemical screening and GC-MS analysis of methanol extract of Ceropegia pusilla. Int J Res Appl Nat Soc Sci 2013;1:49-58.

17. Selvamangai C, Bhaskar A. GC-MS analysis of phytocomponents in the methanolic extract of Eupatorium triplinerve. Int J Drug Dev 2010;4:148-53.

18. Selvakumar S, Valliammai R. Determination of bioactive and pharmaceutical components of Croton boripladianus by GC-MS analysis. Int J Pharm Sci Nanotechnol 2016;9:1-6.

19. Gupta AK, Bhat JL. GC-MS analysis of methanol extract of Acacia nilotica (L.) Leaves. Int J Pharm Chem 2016;6:50-3. 